Review

\title{
miR-552: an important post-transcriptional regulator that affects human cancer
}

\author{
Yuhao Zou, Xin Zhao ${ }^{\bowtie}$, Yin Li, Shiwei Duan ${ }^{\bowtie}$ \\ Medical Genetics Center, Ningbo University School of Medicine, Ningbo, Zhejiang, China. \\ $\square$ Corresponding authors: Shiwei Duan (E-mail: duanshiwei@nbu.edu.cn) and Dr. Xin Zhao (E-mail: zhaoxin@nbu.edu.cn). \\ (c) The author(s). This is an open access article distributed under the terms of the Creative Commons Attribution License (https://creativecommons.org/licenses/by/4.0/). \\ See http://ivyspring.com/terms for full terms and conditions.
}

Received: 2020.04.02; Accepted: 2020.08.14; Published: 2020.08.27

\begin{abstract}
MiR-552 is a small non-coding RNA located on chromosome 1p34.3, and its expression level is significantly up-regulated in tissues or cells of various tumors. miR-552 can target multiple genes. These targeted genes play important regulatory roles in biological processes such as gene transcription and translation, cell cycle progression, cell proliferation, apoptosis, cell migration, and invasion. Besides, miR-552 may affect the efficacy of various anticancer drugs by targeting genes such as TP53 and RUNX3. This review summarizes the biological functions and clinical expressions of miR-552 in human cancer. Our goal is to explore the potential value of miR-552 in the diagnosis, prognosis, and treatment of human cancer.
\end{abstract}

Key words: miR-552; cancer; diagnosis; prognosis; drug resistance

\section{Introduction}

MicroRNAs (miRNAs) are a class of non-coding small RNAs with a length of about $22 \mathrm{bp}$. They mostly bind to the 3 'untranslated region (3'UTR) of the mRNA, thereby regulating the expression of most genes after transcription [1]. Compared with normal tissues, miR-552 expression is up-regulated in many tumors, including colorectal cancer (CRC) [2], Hepatocellular carcinoma (HCC) [3], ampulla adenocarcinoma [4], gastric cancer (GC) [5], and rectal adenocarcinoma (READ) [5], osteosarcoma (OS) [6], lung cancer (LCA) [7], papillary mucinous tumor (IPMN) [8], and ovarian cancer (OC) [9]. By targeting multiple genes, miR-552 can promote cell cycle progression [10], cell proliferation, migration, and invasion [3], thereby leading to tumorigenesis and cancer development. At the same time, miR-552 can also play a role in suppressing tumors by promoting apoptosis [11]. miR-552 can affect the resistance of cancer cells to anti-cancer drugs by targeting SMAD2, TP53, and RUNX3. Here, this review summarizes miR-552-related biological functions and mechanisms in human tumors. We aim to improve our understanding of its clinical significance in the diagnosis, prognosis, and treatment of tumors.

\section{miR-552 family}

The miR-552 family is located on chromosome 1 (chr1: 189966305-189966399). The family includes two main members of the human genome, which are defined by hsa-miR-552-5p (miR-552) and hsa-miR-552-3p, respectively. Both mature sequences are 21 nucleotides in length and are highly conserved (Figure 1). Currently, most hsa-miR-552 studies are related to miR-552. Based on the information of miRbase, the sequence of miR-552-5p (miR-552) is guuuaaccuuuugccuguugg, and the sequence of miR-552-3p is aacaggugacugguuagacaa.

\section{The molecular function of miR-552 target gene}

MiR-552 regulates the expression of various genes after transcription by directly binding to the 3'UTR of the target gene mRNA. The target genes of miR-552 have unique molecular functions, such as catalytic activity, transcriptional regulation, and binding. 


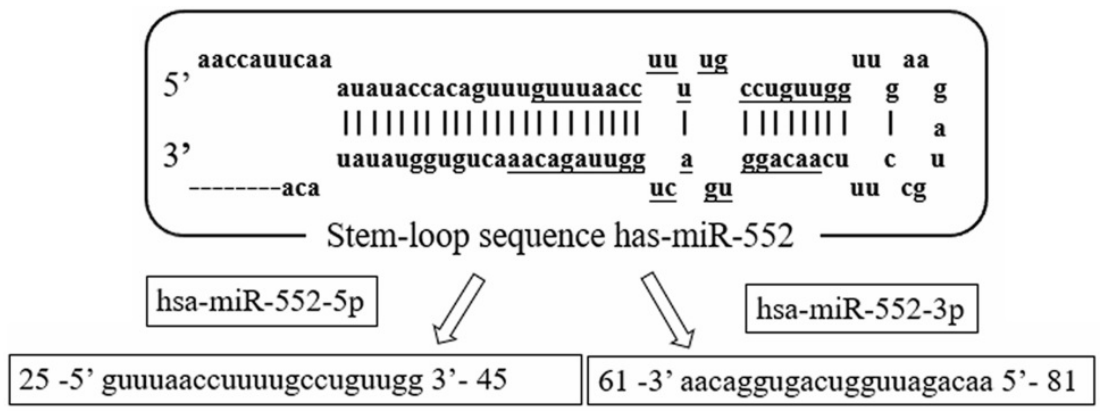

Figure 1. The sequence structure of miR-552 family. Hsa-miR-552 is located on chromosome 1(chr1: 189966305-189966399). It has two mature sequences, hsa-miR-552-5p (miR-552) and hsa-miR-552-3p.

Adhesion junction-associated protein 1 (AJAP1) is described as a novel component of adhesion junctions in polarized epithelial cells. Some studies have suggested that AJAP1 may bind to each other through $\beta$-catenin and E-cadherin-mediated binding complexes [12]. Wnt inhibitor factor 1 (WIF-1) is a tumor suppressor gene that mainly encodes secreted proteins. Normally, it can inhibit the Wnt / $\beta$-catenin pathway by binding to Wnt protein signal transduction [13]. TIMP2 is a natural inhibitor of matrix metalloproteinases. Matrix metalloproteinases are a group of peptidases involved in extracellular matrix degradation. TIMP2 can preferentially bind to proMMP-2 [14]. RUNX3 is a member of the RUNX family of transcription factors. It can inhibit the transcription of superoxide dismutase 3 (SOD3) by binding to the SOD3 promoter to induce the production of reactive oxygen species, thereby affecting the apoptosis of CRC [15].

\section{The clinical significance of $\mathrm{miR}-552$ in human cancer}

Current research shows that miR-552 is upregulated in at least 12 cancers (Table 1). Compared with adjacent tissues, the expression level of miRNA-552 in colorectal cancer (CRC) tissues was up-regulated [16]. This is consistent with the results of five previous independent studies [2, 17-19]. And the miR-552 is expressed in CRC more than three times the normal tissue [16, 20-23]. The miR-552 expression was also significantly up-regulated in various CRC cell lines including HCT116, HT-29, HCT-15, and HT-29 [21-24]. Consistent with this, miR-552 was also found to be up-regulated in the serum of CRC patients [25]. Comparing miR-552 expression in 158 pairs of colon cancer (CC) adenocarcinoma tissues with proficient DNA mismatch repair (pMMR) and adjacent tissues found that miR-552 expression was significantly associated with CC risk [20]. In liver cancer (HCC), Qu W et al. detected the expression levels of miR-552 in 81 pairs of HCC tissues and adjacent non-tumor tissues and found that miR-552 expression levels in HCC tissues were increased [3], which was found in the other two independent studies [26, 27]. Han $\mathrm{T}$ et al. found that miR-552 was overexpressed in liver tumor-initiating cells (T-ICs) [28]. In 107 cases of ampullary adenocarcinoma, the expression of miRNA-552 was also significantly upregulated [4]. Through the comparison of 122 gastric cancer (GC) tissues and matched adjacent tissues, Feng $X$ et al found that miR-552 was up-regulated in GC tissues. This result was found in various GC cell lines (AGS, MGC-803, and MKN-45) [29]. In rectal adenocarcinoma (READ), Lai $\mathrm{CH}$ et al. found that the expression of miR-552 in READ tissues $(n=162)$ was much higher than normal tissues $(n=3)$ in TCGA database [30]. By comparing the expression of miR552 between 51 osteosarcomas (OS) tissues and 19 adjacent normal tissues, it was found that the expression level of miR-552 was significantly increased in OS tissues [6]. This was confirmed by other OS studies [31, 32]. Kim HK et al. found that miR-552 was up-regulated in 35 lung cancer (LCA) tissues [7]. And miR-552 expression was significantly increased in two paraffin-embedded intraductal papillary mucinous tumor (IPMN) tissues and four pancreatic cancer cell lines (Panc1, MiaPaCa-2, XPA-3, BxPC-3, and HPNE) [8]. In ovarian cancer (OC), Zhao $\mathrm{W}$ et al. found that the expression of miR-552 in OC tissues and cells (HO8910 and HGSOCO) was upregulated [9] compared with non-tumor tissues and non-tumor cell lines. In pancreatic cancer (PC), miR-552 is up-regulated in PC tissues and cells (CFPAC-1, AsPC-1, MIA-PaCa2, Capan-2, BXPC-3, and PANC-1) compared to normal PC and cell lines [33]. Gu J et al. found that miR-552 was up-regulated in 20 cases of laryngeal carcinoma and four laryngeal cancer cell lines (M2E, M4E, TU212, and Hep-2). In addition, they also found that miR-552 expression level was higher in stage 3/4 laryngeal cancer patients than that in patients with stage $1 / 2$ laryngeal carcinoma [34]. Through microarray analysis of 29 oral squamous cell carcinoma (OSCC) samples, Mayakannan Manikandan et al. found that miR-552 was up-regulated in OSCC [35]. 
Table 1. miR-552 is up-regulated in multiple cancer tissues and cells

\begin{tabular}{|c|c|c|c|}
\hline Cancer type & Tissues or cell lines & $\begin{array}{l}\text { Target } \\
\text { gene }\end{array}$ & Reference \\
\hline \multirow[t]{11}{*}{ CRC } & $\begin{array}{l}183 \text { CRC tissues and } 183 \text { matched } \\
\text { normal tissues }\end{array}$ & & {$[61]$} \\
\hline & $\begin{array}{l}20 \text { CRC tissues and } 183 \text { matched } \\
\text { normal tissues }\end{array}$ & DACH1 & [19] \\
\hline & $\begin{array}{l}50 \mathrm{CRC} \text { tissues and } 50 \text { matched } \\
\text { normal tissues }\end{array}$ & ADAM28 & {$[18]$} \\
\hline & $97 \mathrm{CRC}$ tissues & SMAD2 & [2] \\
\hline & Cell (HCT116) & ТР53 & [24] \\
\hline & Cell (HT-29) & & [21] \\
\hline & $\begin{array}{l}6 \text { CRCs and } 6 \text { matched normal } \\
\text { tissues; Cell (HT-29) }\end{array}$ & & [23] \\
\hline & Cells (HCT-15, HT-29) & & {$[22]$} \\
\hline & $\begin{array}{l}55 \text { normal tissues, } 11 \text { IBD-dysplasias, } \\
\text { and } 38 \text { frank IBD-cancers }\end{array}$ & & [17] \\
\hline & $44 \mathrm{mCRC}$ blood samples & & [25] \\
\hline & $\begin{array}{l}158 \text { pMMR adenocarcinomas and } 64 \\
\text { adenocarcinomas dMMR }\end{array}$ & & {$[20]$} \\
\hline \multirow[t]{4}{*}{$\mathrm{HCC}$} & $\begin{array}{l}81 \text { pairs of HCC tissues and matched } \\
\text { adjacent tissues }\end{array}$ & AJAP1 & [3] \\
\hline & $\begin{array}{l}76 \text { pairs of HCC tissues and matched } \\
\text { adjacent tissues }\end{array}$ & WIF1 & {$[27]$} \\
\hline & $\begin{array}{l}15 \text { pairs of HCC and matched } \\
\text { adjacent tissues; Cell (HCC) }\end{array}$ & RUNX3 & [26] \\
\hline & 110 HCC tissues; Cell(T-Ics) & PTEN & {$[28]$} \\
\hline $\begin{array}{l}\text { Ampullary } \\
\text { Adenocarcinoma }\end{array}$ & 107 ampullary adenocarcinomas & & [4] \\
\hline GC & $\begin{array}{l}122 \text { pairs of GC tissues and matched } \\
\text { adjacent tissues; Cells (GES-1 and } \\
\text { AGS, MGC-803, MKN-45) }\end{array}$ & & [5] \\
\hline READ & $\begin{array}{l}162 \text { READ tissues and } 3 \text { normal } \\
\text { tissues }\end{array}$ & & {$[30]$} \\
\hline \multirow[t]{3}{*}{ OS } & $\begin{array}{l}51 \text { OS tissues and } 19 \text { adjacent normal } \\
\text { tissues }\end{array}$ & WIF1 & [6] \\
\hline & $\begin{array}{l}67 \text { OS tissues and } 67 \text { adjacent normal } \\
\text { tissues }\end{array}$ & TIMP2 & {$[31]$} \\
\hline & 323 OS Cells & & [32] \\
\hline LCA & $\begin{array}{l}35 \text { lung carcinomas tissues and } 2 \\
\text { adjacent normal lung tissues }\end{array}$ & & [7] \\
\hline IPMN & $\begin{array}{l}2 \text { IPMN tissues; Cells (Panc1, } \\
\text { MiaPaCa-2, XPA-3, BxPC-3, HPNE) }\end{array}$ & & [8] \\
\hline OC & $\begin{array}{l}80 \text { pairs of OC tissues and matched } \\
\text { adjacent normal tissues; Cells } \\
\text { (HO8910, HGSOCO) }\end{array}$ & PTEN & [9] \\
\hline PC & $\begin{array}{l}54 \text { PC tissues and } 54 \text { adjacent normal } \\
\text { tissues; Cells (CFPAC-1, AsPC-1, } \\
\text { MIA-PaCa2, Capan-2, BXPC-3, } \\
\text { PANC-1) }\end{array}$ & FOXO3 & {$[33]$} \\
\hline $\begin{array}{l}\text { Laryngeal } \\
\text { carcinoma }\end{array}$ & $\begin{array}{l}20 \text { laryngeal carcinoma tissues; Cells } \\
\text { (M2E, M4E, TU212 and Hep-2) }\end{array}$ & & {$[34]$} \\
\hline OSCC & $\begin{array}{l}29 \text { OSCC tissues and } 61 \text { verification } \\
\text { sample }\end{array}$ & & [35] \\
\hline
\end{tabular}

Compared with normal tissues, the fold increase of miR-552 expression is different in different cancer tissues. MiR-552 is expressed in CRC more than three times the normal tissue [16, 20-23]. The expression of miR-552 in HCC is more than twice that of normal tissues [3]. The expression of miR-552 in READ is 3.20 times that of normal tissues [30]. Compared with normal tissues, the expression level of miR-552 in metastatic lung adenocarcinomas is 39 times higher [7]. The expression of miR-552 in IPMN is more than three times that of normal tissues [8]. Also, the expression of miR-552 in OS cells was 5.01 times that of normal cells [32].

These results indicate that the abnormal expression of miR-552 in cancer tissues and cells may be closely related to the occurrence and development of cancer.

\section{The biological role of miR-552 in human cancer}

\section{Regulation of gene transcription and translation}

As a member of the CYP family, CYPE1 can convert carcinogens and inactive xenobiotics into reactive metabolites [36]. Studies have found that the cruciform structure in gene promoters is usually involved in transcriptional regulation [37]. miR-552 can form DNA-RNA hybrids with CYP2E1 and regulate the expression of CYP2E1, thereby inhibiting the transcription and translation in the HCC cell nucleus and cytoplasm [38]. In HCC HepG2 cells, the non-seed region of nuclear miR-552 (AACAGAUUG GUCA) binds to the cruciform structure of the CYP2E1 promoter and inhibits transcription of CYP2E1, while the seed region of cytoplasmic miR552 (GUGGACAA) can bind the 3' UTR of CYP2E1 mRNA and thus inhibit translation of CYP2E1 [38].

\section{Cell cycle regulation}

The cell cycle is an important process of cell proliferation. The abnormal cell cycle is closely related to the proliferation of cancer cells.

MiR-552 inhibits the expression of WIF1 and may promote the cell cycle of glioblastoma cells [10]. Down-regulation of WIF1 expression induced by miR-552 can cause glioblastoma to significantly reduce the number of cells in the $S$ phase and increase the number of cells in the G1 phase, thereby inhibiting cell growth and differentiation [10]. Cyclin D3 (CCND3) is part of the D-type cyclin and mainly regulates the G1/S phase transition of the cell cycle $[39,40]$. In CRC, miR-552 inhibitors can decrease the expression of cyclin and c-Myc [19].

\section{Cell proliferation and apoptosis}

Recent studies have shown that miR-552 is related to the proliferation of cancer cells (Figure 2).

The Src pathway is an important signaling pathway that mediates the proliferation of cancer cells [41], while the AJAP1is inversely related to the expression of Src protein [42]. Overexpression of miR-522 can inhibit AJAP1, thereby increasing the 
level of Src protein suppressed by AJAP1, leading to a large number of HCC cell proliferation [3]. Abnormal Wnt/ $\beta$-catenin pathway may lead to cell proliferation and malignant transformation [43, 44], of which WIF1 plays a tumor-suppressive role by directly binding to Wnt protein [45]. In HCC, miR-552 binds to the 3'-UTR of WIF1 mRNA to form an RNA-induced silencing complex (RISC), which inactivates the Wnt/ $\beta$-catenin signaling pathway to promote cell proliferation [27]. HER2 belongs to the receptor tyrosine kinase of the epidermal growth factor receptor (EGFR) family [46]. In contrast, miR-552 can inhibit HER2 expression by directly binding 3'-UTR of HER2 [47], and induce breast cancer cell apoptosis [11].

As a transcription factor, p53 plays a central role in tumor suppression mainly through the transcriptional regulation of many target genes [48]. miR-552 can down-regulate the expression of p53 and promote cell proliferation, thereby showing oncogenic properties in the CRC and GC $[24,34]$.

DACH1 is a tumor suppressor gene that has been shown to be down-regulated in a variety of diseases such as breast cancer, prostate cancer and endometrial cancer [49]. In CRC, miR-552 inhibits DACH1 expression at the post-transcriptional level and enhances the function of the Wnt/ $\beta$-catenin signaling pathway to promote CRC cell proliferation [19].

ADAM28 is a transmembrane and secreted protein of the $\mathrm{A}$ integrin and metalloproteinase (ADAM) family, and it can affect cell adhesion and migration [50]. ADAM28 is involved in the growth and metastasis of solid tumors and the progress of hematological malignancies [51]. miR-552 can directly target ADAM28 and inhibit its expression, thereby promoting CRC cell proliferation through the Src/MEK/PI3K signaling pathway [18].

As a highly homologous protein, SMAD2 is a mediator that mediates multiple signaling pathways and is a direct mediator of transforming growth factor (TGF- $\beta$ ) [52]. Activation of the TGF- $\beta$ signaling pathway provides growth-suppressing signals in the normal intestinal epithelium [53]. When miR-552 targets the inhibition of SMAD2, the growth of 5-FU resistant CRC tumor cells can be inhibited by TGF- $\beta$ [2]. PTEN is a dual-function phosphatase and tensin homolog located on chromosome 10 and is a tumor suppressor gene associated with a variety of malignancies [54]. A study has shown that miR-552 down-regulates PTEN and activates AKT phosphorylation in liver T-ICs, which is conducive to promoting liver T-ICs expansion [28]. Zhao $\mathrm{W}$ et al found that miR-552 can directly regulate PTEN expression through its 3'-UTR interaction and promote the development of OC cells [9].

Bcl-2 can inhibit the dimerization of Bax, thereby reducing caspase-3-mediated apoptosis [55, 56]. RUNX3 is a tumor suppressor gene that regulates gene expression related to cell viability [57]. Studies have found that miR-552 can increase the expression of Bcl-2 in HCC cells by targeting RUNX3, and reduce the expression of caspase 3 and Bax, thereby inhibiting the apoptosis of HCC cells [26].

\section{EMT}

Epithelial-mesenchymal transition (EMT) is an important biological process for epithelial cellsderived malignant tumor cells to acquire the ability to migrate and invade [58] (Figure 3).

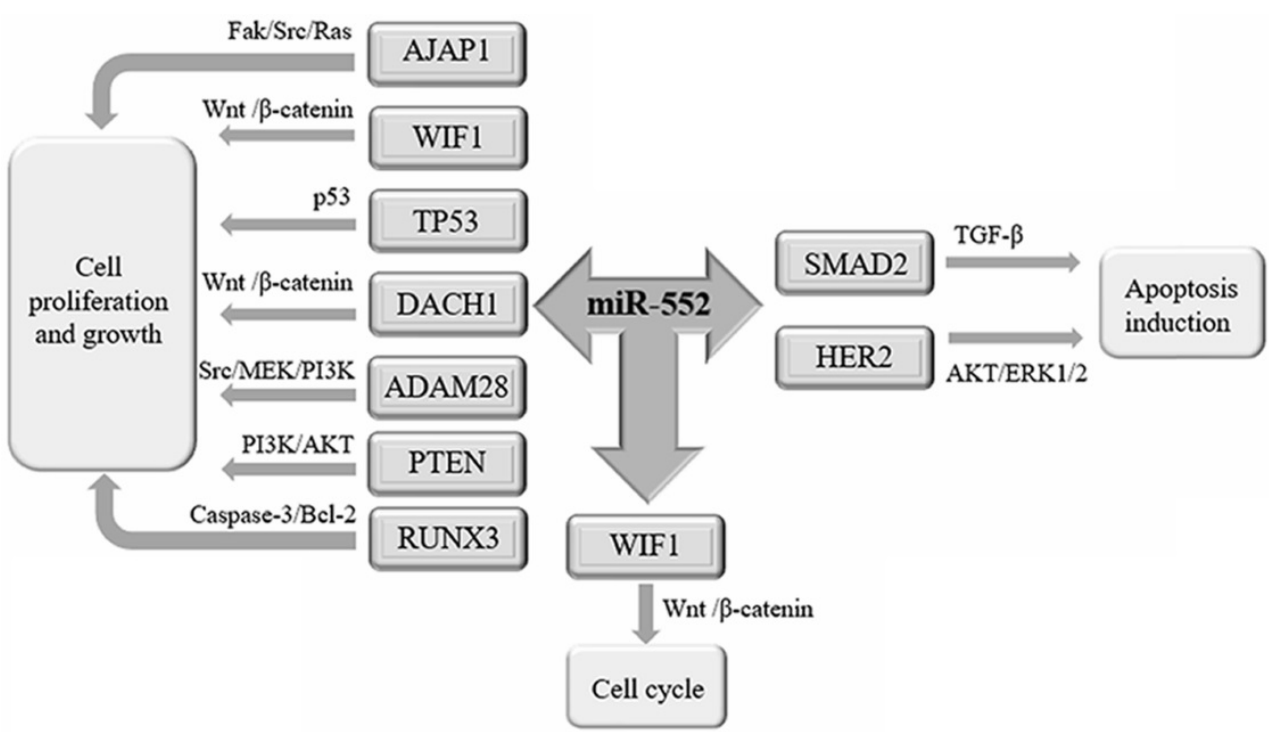

Figure 2. The biological function of miR-552 in cancer. miR-552 is involved in the development and progression of tumors through its target genes. miR-552 targets AJAP1, WIF1, TP53, DACH1, ADAM28, PTEN, and RUNX3 to promote cell proliferation and growth. miR-552 targets SMAD2, HER2 promotes apoptosis. By inhibiting the expression of WIF1, miR-552 can promote the cell cycle of cancer cells. 


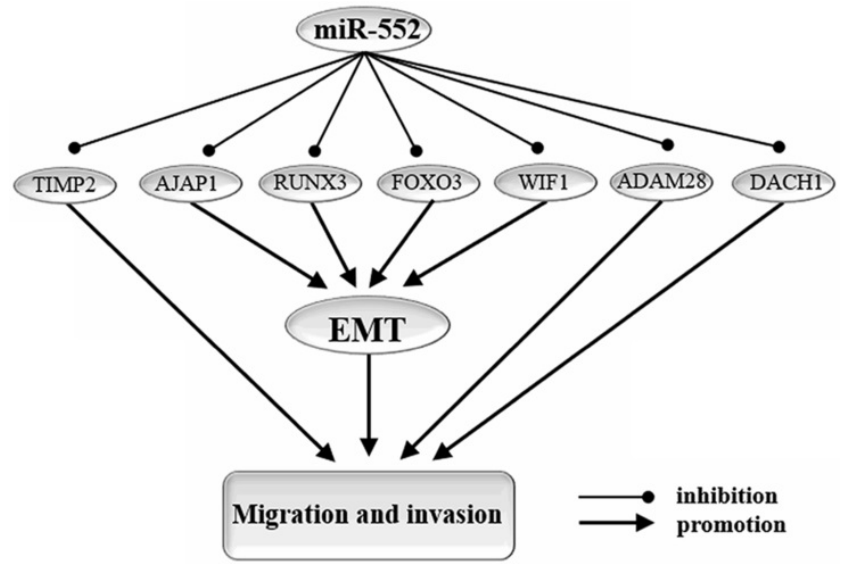

Figure 3. miR-552 targets genes that affect cell migration, invasion, and EMT. EMT: epithelial-to-mesenchymal transition. By targeting AJAPI, RUNX3, WIF1, FOXO3, miR-552 reverses the process of EMT and thereby inhibits migration and invasion of cancer cells. In addition, miR-552 regulates cell migration and invasion in cancer through other pathways. miR-552 promotes cell migration and invasion in cancer by targeting TIMP2, ADAM28, and DACH16.

MiR-552 can promote the development of EMT by targeting AJAP1 [3], WIF1 [27], RUNX3 [26], and FOXO3 [33]. In HCC cells, miR-552 increased the expression level of E-cadherin and down-regulated the expression of $\mathrm{N}$-cadherin and vimentin by down-regulating the expression of AJAP1 [3]. In the HCC HIF3B cell line, miR-552 could down-regulate WIF1 expression, increase the effect of E-cadherin, and promote the EMT pathway [27]. miR-552 can target RUNX3 by inhibiting miR-186/E-cadherin/ EMT pathway, thereby promoting cell migration and invasion of HCC cells [26, 57]. Forkhead box protein O3 (FOXO3) is a member of the Forkhead box-O transcription factor, which participates in the EMT process by regulating the Wnt signaling pathway and has been shown to play a key role in PC $[59,60]$. miR-552 can up-regulate the expression of $\mathrm{FOXO} 3$ in $\mathrm{PC}$ and inhibit the Wnt signaling pathway, thereby inhibiting EMT and PC cell migration [33].

\section{Cell migration and invasion}

Cell migration and invasion are important features of various cancers and are the main causes of high cancer mortality [26]. miR-552 can promote the expression of MMP, which significantly promotes the migration and invasion of OS MG63 cells [31]. As a member of the TIMP family, TIMP2 can inhibit MMP, thereby reducing the degradation of the extracellular matrix and inhibiting the migration and invasion of primary tumor cells [61, 62]. ADAM28 acts as a "signaling scissor" in various membrane environments [50, 63]. miR-552 targets the ADAM28 gene to promote the migration and invasion of CRC cells, thereby enhancing the carcinogenesis effect [18]. Increased expression of DACH1 can inhibit the abundance of c-Myc [19]. miR-552 activates the
Wnt/ $\beta$-catenin signaling pathway by regulating $\mathrm{DACH} 1$ expression, thereby promoting the proliferation and migration of CRC [19].

\section{miR-552 and drug resistance in cancer cells}

The antimetabolite drug 5-fluorouracil (5-FU) can improve the 12-month survival rate of CRC patients [64]. SMAD2 phosphorylation can promote the occurrence of cancer and increase cell resistance [65]. The miR-552/SMAD2 cascade plays a key role in regulating the response of cells to 5-FU chemotherapy. miR-552 can down-regulate the expression of SMAD2, and the low expression of miR-552 and the high expression of SMAD2 can play a synergistic role to promote 5-FU resistance of cancer cells, which is not conducive to the treatment of CRC [2]. However, miR-552 is significantly up-regulated in CRC side population (SP) cells which are resistant to multiple cancer drugs [22].

TP53 is an important tumor suppressor. The wild-type TP53 neuroblastoma cell line is very sensitive to the synergistic treatment of doxorubicin and GSK2830371, an antagonist of phosphatase 1 (WIP1) [66]. Targeted inhibition of TP53 by miR-552 may reduce the sensitivity of neuroblastoma cell lines to drugs, thereby inhibiting the effect of drugs on cancer cells [24].

Increased methylation of the cancer suppressor gene RUNX3 reduces RUNX3 gene expression, which increases the risk of CRC [67]. In CRC, methylation of RUNX3 can inhibit the therapeutic effect of the chemotherapeutic drug irinotecan, resulting in a poor prognosis for patients with CRC [68]. Targeted inhibition of RUNX3 by miR-552 may inhibit the therapeutic effect of chemotherapy drugs [26].

Celecoxib is an inhibitor of cyclooxygenase-2 (COX-2), which can inhibit the growth of tumor cells $[69,70]$. When celecoxib was used to treat HT-29 CRC cells, the expression of miR-552 was down-regulated by 2.1 times compared with control cell lines, which was beneficial to the treatment of CRC [71].

\section{miR-552-3p and human cancer}

MiR-552-3p is the antisense strand of miR-552, and there is little research on miR-552-3p and cancer. Wei $\mathrm{Z}$ et al. analyzed miRNA-Seq data of GC and found that compared with normal tissues, miR-552-3p expression was up-regulated nearly 3.55 times in GC [72]. Survivin is a well-known target for cancer treatment. Fengzhi Li et al. found from the GeneGo database that miR-552-3p can be combined with survivin transcription to inhibit cancer progress, which is helpful for anti-cancer against survivin [73]. And some studies have found that circFUT8 may competitively bind to miR-552-3p, thereby 
eliminating the inhibition of related target genes and related to the progress of HCC [74]. Overexpression of miR-552-3p can reduce the level of CCND3, thereby inhibiting the cell cycle and proliferation of NCI-H460 LCA cells [75]. However, the specific mechanism of miR-552-3p remains to be studied.

\section{miR-552 and cancer prognosis}

MiR-552 is significantly associated with cancer prognosis in many studies. The expression of miR-552 was up-regulated in CRC tumor tissues, and the up-regulation of miR-552 expression was significantly associated with decreased survival in CRC patients [16]. miR-552 is significantly upregulated in CC resistant cells (SP cells) [22]. Besides, in CRC patients receiving 5-FU chemotherapy, the down-regulated miR-552 expression can increase overall survival in CRC patients [2]. In HCC cells, miR-552 overexpression can target the inhibition of AJAP1, which promotes the migration, invasion, and EMT of HCC cells, and is associated with poor prognosis in HCC patients [3]. The high expression of miR-552 in HCC is associated with malignant clinicopathological features and decreased survival [27]. High levels of miR-552 are associated with poor disease-free survival (DFS) and overall survival in patients [28]. The upregulation of miR-552 is also associated with advanced TNM stage and lymph node metastasis of GC [5]. miR-552 is an independent prognostic factor in patients with GC, and its upregulation is significantly associated with tumors with advanced TNM staging, lymph node metastasis, intestinal metaplasia, and genomically stable subtypes of tumors. Moreover, in GC patients with high expression of miR-552, the overall survival time is lower than that of patients with low expression [29]. The miR-552 expression is up-regulated in OS tissues and cell lines, which inhibits TIMP2 to promote cell migration and invasion, and ultimately leads to poorer prognosis for patients with OS [31]. Xiaobo Shi et al. used ten characteristic RNAs including miR-552 for esophageal squamous cell carcinoma (ESCC) prognostic scoring and found that miR-552 is a dangerous RNA that causes ESCC [76].

\section{Regulation of miR-552 transcription}

NGX6 is a tumor suppressor gene that plays an important role in nasopharyngeal and CRC [77, 78]. NGX6 is able to inhibit Cyclin D1 expression, thereby delaying the cell cycle and promoting apoptosis [77]. Wang XY et al. found that NGX6 could up-regulate the expression of miR-552 [21]. NGX6 was found to participate in the regulation of tumor cell apoptosis, migration, and other functions through the Notch/ JNK molecular signaling pathway [21]. miR-552 is considered to be an important target for Linc00261 in
PC. Chen $\mathrm{T}$ et al. found that Linc00261 can upregulate the expression of $\mathrm{FOXO} 3$ by inhibiting the expression of miR-552 to inhibit the Wnt signaling pathway, and finally weaken the EMT and cell migration process of PC [33].

\section{Conclusions}

This review summarizes the research progress of miR-552 in human cancer. The target genes of miR-552 have a series of molecular functions, such as catalytic activity, transcriptional regulation, and binding. The expression of miR-552 is up-regulated in at least 12 cancers, which makes it possible to become a molecular marker for cancer diagnosis. In addition, miR-552 can also be used as a prognostic marker in cancer patients, because the increased expression of miR-552 in cancer is related to the poor survival level of patients. In cancer, miR-552's target genes are involved in a variety of biological processes, such as transcription and translation, cell cycle, cell proliferation and apoptosis, EMT, cell migration and invasion. miR-552 can also suppress or promote the effects of cancer drugs by targeting genes. In summary, miR-552 plays a significant role in the initiation and progression of key biological and pathological processes in most of the human cancer. miR-552 can also be used for the diagnosis and prognosis of various cancers. In addition, miR-552-3p can also inhibit the cell cycle and cell proliferation of lung cancer cells. However, the current research on miR-552-3p is still lacking. In the future, it is necessary to explore its relationship with more cancers.

\section{Acknowledgments}

\section{Authors' contributions}

$\mathrm{SD}, \mathrm{XZ}$, and $\mathrm{YZ}$ conceived the review. $\mathrm{XZ}$ and $\mathrm{YL}$ collated and analyzed the literature. SD and $Y Z$ help to complete the chart and write the manuscript.

\section{Competing Interests}

The authors have declared that no competing interest exists.

\section{References}

1. Lu TX, Rothenberg ME. MicroRNA. The Journal of allergy and clinical immunology. 2018; 141: 1202-7.

2. Zhao P, Ma YG, Zhao Y, Liu D, Dai ZJ, Yan CY, et al. MicroRNA-552 deficiency mediates 5 -fluorouracil resistance by targeting SMAD2 signaling in DNA-mismatch-repair-deficient colorectal cancer. Cancer chemotherapy and pharmacology. 2019; 84: 427-39.

3. Qu W, Wen X, Su K, Gou W. MiR-552 promotes the proliferation, migration and EMT of hepatocellular carcinoma cells by inhibiting AJAP1 expression. Journal of cellular and molecular medicine. 2019; 23: 1541-52.

4. Schultz NA, Werner J, Willenbrock H, Roslind A, Giese N, Horn T, et al. MicroRNA expression profiles associated with pancreatic adenocarcinoma and ampullary adenocarcinoma. Modern pathology : an official journal of the United States and Canadian Academy of Pathology, Inc. 2012; 25: 1609-22.

5. Feng X, Zhu M, Liao B, Tian T, Li M, Wang Z, et al. Upregulation of miR-552 Predicts Unfavorable Prognosis of Gastric Cancer and Promotes the 
Proliferation, Migration, and Invasion of Gastric Cancer Cells. Oncology research and treatment. 2020; p: 1-8.

6. Cai W, Xu Y, Yin J, Zuo W, Su Z. miR-552-5p facilitates osteosarcoma cell proliferation and metastasis by targeting WIF1. Experimental and therapeutic medicine. 2019; 17: 3781-8.

7. Kim HK, Lim NJ, Jang SG, Lee GK. miR-592 and miR-552 can distinguish between primary lung adenocarcinoma and colorectal cancer metastases in the lung. Anticancer research. 2014; 34: 2297-302.

8. Park YG, Lee KH, Lee JK, Lee KT, Choi DW, Choi SH, et al. [MicroRNA expression pattern in intraductal papillary mucinous neoplasm]. The Korean journal of gastroenterology = Taehan Sohwagi Hakhoe chi. 2011; 58: 190-200.

9. Zhao W, Han T, Li B, Ma Q, Yang P, Li H. miR-552 promotes ovarian cancer progression by regulating PTEN pathway. Journal of ovarian research. 2019; 12: 121.

10. Wu J, Fang J, Yang Z, Chen F, Liu J, Wang Y. Wnt inhibitory factor-1 regulates glioblastoma cell cycle and proliferation. Journal of clinical neuroscience : official journal of the Neurosurgical Society of Australasia. 2012; 19: 1428-32.

11. Leivonen SK, Sahlberg KK, Makela R, Due EU, Kallioniemi O, Borresen-Dale $\mathrm{AL}$, et al. High-throughput screens identify microRNAs essential for HER2 positive breast cancer cell growth. Molecular oncology. 2014; 8: 93-104.

12. Bharti S, Handrow-Metzmacher H, Zickenheiner S, Zeitvogel A, Baumann R, Starzinski-Powitz A. Novel membrane protein shrew-1 targets to cadherin-mediated junctions in polarized epithelial cells. Molecular biology of the cell. 2004; 15: 397-406.

13. Zheng $\mathrm{Y}, \mathrm{Li} \mathrm{X}$, Jiang $\mathrm{Y}, \mathrm{Xu} \mathrm{Y}$, Song $\mathrm{B}$, Zhou $\mathrm{Q}$, et al. Promoter hypermethylation of Wnt inhibitory factor-1 in patients with lung cancer: A systematic meta-analysis. Medicine. 2016; 95: e5433.

14. Ries C. Cytokine functions of TIMP-1. Cellular and molecular life sciences: CMLS. 2014; 71: 659-72.

15. Kim BR, Park SH, Jeong YA, Na YJ, Kim JL, Jo MJ, et al. RUNX3 enhances TRAIL-induced apoptosis by upregulating DR5 in colorectal cancer. Oncogene. 2019; 38: 3903-18.

16. Wang N, Liu W. Increased expression of miR-552 acts as a potential predictor biomarker for poor prognosis of colorectal cancer. European review for medical and pharmacological sciences. 2018; 22: 412-6.

17. Olaru AV, Yamanaka S, Vazquez C, Mori Y, Cheng Y, Abraham JM, et al. MicroRNA-224 negatively regulates p21 expression during late neoplastic progression in inflammatory bowel disease. Inflammatory bowel diseases. 2013; 19: 471-80.

18. Wang J, Li H, Wang Y, Wang L, Yan X, Zhang D, et al. MicroRNA-552 enhances metastatic capacity of colorectal cancer cells by targeting a disintegrin and metalloprotease 28. Oncotarget. 2016; 7: 70194-210.

19. Cao J, Yan XR, Liu T, Han XB, Yu JJ, Liu SH, et al. MicroRNA-552 promotes tumor cell proliferation and migration by directly targeting $\mathrm{DACH} 1$ via the $\mathrm{Wnt} /$ beta-catenin signaling pathway in colorectal cancer. Oncology letters. 2017: 14: 3795-802.

20. Oberg AL, French AJ, Sarver AL, Subramanian S, Morlan BW, Riska SM, et al. miRNA expression in colon polyps provides evidence for a multihit model of colon cancer. PloS one. 2011; 6: e20465.

21. Wang XY, Wu MH, Liu F, Li Y, Li N, Li GY, et al. Differential miRNA expression and their target genes between NGX6-positive and negative colon cancer cells. Molecular and cellular biochemistry. 2010 345: 283-90.

22. Xia ZS, Wang L, Yu T, Zhong W, Lian GD, Wu D, et al. MiR-5000-3p, miR-5009-3P and miR-552: potential microRNA biomarkers of side population cells in colon cancer. Oncology reports. 2014; 32: 589-96.

23. Chen WC, Lin MS, Ye YL, Gao HJ, Song ZY, Shen XY. microRNA expression pattern and its alteration following celecoxib intervention in human colorectal cancer. Experimental and therapeutic medicine. 2012; 3: 1039-48.

24. Kwak B, Kim DU, Kim TO, Kim HS, Kim SW. MicroRNA-552 links Wnt signaling to p53 tumor suppressor in colorectal cancer. International journal of oncology. 2018; 53: 1800-8.

25. de Miguel Perez D, Rodriguez Martinez A, Ortigosa Palomo A, Delgado Urena M, Garcia Puche JL, Robles Remacho A, et al. Extracellular vesicle-miRNAs as liquid biopsy biomarkers for disease identification and prognosis in metastatic colorectal cancer patients. Scientific reports. 2020; 10: 3974

26. Ma Y, Ma M, Ma L, Zhang F, Liu Y, Ma X. Downregulation of miR-552 in hepatocellular carcinoma inhibits cell migration and invasion, and promotes cell apoptosis via RUNX3. Experimental and therapeutic medicine. 2019; 18: 3829-36.

27. Li C, Wang Z, Chen S, Zhang J, Qu K, Liu C. MicroRNA-552 promotes hepatocellular carcinoma progression by downregulating WIF1. International journal of molecular medicine. 2018; 42: 3309-17.

28. Han T, Zhang Y, Yang X, Han L, Li H, Chen T, et al. miR-552 Regulates Liver Tumor-Initiating Cell Expansion and Sorafenib Resistance. Molecular therapy Nucleic acids. 2020; 19: 1073-85.

29. Feng X, Zhu M, Liao B, Tian T, Li M, Wang Z, et al. Upregulation of miR-552 Predicts Unfavorable Prognosis of Gastric Cancer and Promotes the Proliferation, Migration, and Invasion of Gastric Cancer Cells. Oncology research and treatment. 2020; 43: 103-11.

30. Lai CH, Liang XZ, Liang XY, Ma SJ, Li JG, Shi MF, et al. Study on miRNAs in Pan-Cancer of the Digestive Tract Based on the Illumina HiSeq System Data Sequencing. BioMed research international. 2019; 2019: 8016120.
31. Chao Y, Hu K, Wang X, Wang L. MicroRNA-552 promotes migration and invasion of osteosarcoma through targeting TIMP2. Biochemical and biophysical research communications. 2019; 511: 63-8.

32. Seckinger A, Meissner T, Moreaux J, Benes V, Hillengass J, Castoldi M, et al. miRNAs in multiple myeloma--a survival relevant complex regulator of gene expression. Oncotarget. 2015; 6: 39165-83.

33. Chen T, Lei S, Zeng Z, Zhang J, Xue Y, Sun Y, et al. Linc00261 inhibits metastasis and the WNT signaling pathway of pancreatic cancer by regulating a miR5525p/FOXO3 axis. Oncology reports. 2020; 43: 930-42.

34. Gu J, Han T, Sun L, Yan AH, Jiang XJ. miR-552 promotes laryngocarcinoma cells proliferation and metastasis by targeting p53 pathway. Cell cycle. 2020; 19: 1012-21.

35. Manikandan M, Deva Magendhra Rao AK, Arunkumar G, Manickavasagam M, Rajkumar KS, Rajaraman R, et al. Oral squamous cell carcinoma: microRNA expression profiling and integrative analyses for elucidation of tumourigenesis mechanism. Molecular cancer. 2016; 15: 28.

36. Li D, Tolleson WH, Yu D, Chen $\mathrm{S}$, Guo L, Xiao W, et al Regulation of cytochrome P450 expression by microRNAs and long noncoding RNAs: Epigenetic mechanisms in environmental toxicology and carcinogenesis. Journal of environmental science and health Part C, Environmental carcinogenesis \& ecotoxicology reviews. 2019; 37: 180-214.

37. Brazda V, Laister RC, Jagelska EB, Arrowsmith C. Cruciform structures are a common DNA feature important for regulating biological processes. BMC molecular biology. 2011; 12: 33

38. Miao L, Yao H, Li C, Pu M, Yao X, Yang H, et al. A dual inhibition: microRNA-552 suppresses both transcription and translation of cytochrome P450 2E1. Biochimica et biophysica acta. 2016; 1859: 650-62.

39. Sherr CJ. D-type cyclins. Trends in biochemical sciences. 1995; 20: 187-90.

40. Cato MH, Chintalapati SK, Yau IW, Omori SA, Rickert RC. Cyclin D3 is selectively required for proliferative expansion of germinal center B cells. Molecular and cellular biology. 2011; 31: 127-37.

41. Lau GM, Lau GM, Yu GL, Gelman IH, Gutowski A, Hangauer D, et al. Expression of Src and FAK in hepatocellular carcinoma and the effect of Src inhibitors on hepatocellular carcinoma in vitro. Digestive diseases and sciences. 2009; 54: 1465-74.

42. Ezaka K, Kanda M, Sugimoto H, Shimizu D, Oya H, Nomoto S, et al. Reduced Expression of Adherens Junctions Associated Protein 1 Predicts Recurrence of Hepatocellular Carcinoma After Curative Hepatectomy. Annals of surgical oncology. 2015; 22 Suppl 3: S1499-507.

43. Suzuki T, Yano H, Nakashima Y, Nakashima O, Kojiro M. Beta-catenin expression in hepatocellular carcinoma: a possible participation of beta-catenin in the dedifferentiation process. Journal of gastroenterology and hepatology. 2002; 17: 994-1000.

44. Chen J, Rajasekaran M, Hui KM. Atypical regulators of Wnt/beta-catenin signaling as potential therapeutic targets in Hepatocellular Carcinoma. Experimental biology and medicine. 2017; 242: 1142-9.

45. Hsieh JC, Kodjabachian L, Rebbert ML, Rattner A, Smallwood PM, Samos CH, et al. A new secreted protein that binds to Wnt proteins and inhibits their activities. Nature. 1999; 398: 431-6.

46. Glynn RW, Miller N, Kerin MJ. 17q12-21 - the pursuit of targeted therapy in breast cancer. Cancer treatment reviews. 2010; 36: 224-9.

47. Iorio MV, Casalini P, Piovan C, Di Leva G, Merlo A, Triulzi T, et al. microRNA-205 regulates HER3 in human breast cancer. Cancer research. 2009; 69: 2195-200.

48. Liu J, Zhang C, Zhao Y, Feng Z. MicroRNA Control of p53. Journal of cellular biochemistry. 2017; 118: 7-14.

49. Yan W, Wu K, Herman JG, Brock MV, Fuks F, Yang L, et al. Epigenetic regulation of DACH1, a novel Wnt signaling component in colorectal cancer. Epigenetics. 2013; 8: 1373-83.

50. Edwards DR, Handsley MM, Pennington CJ. The ADAM metalloproteinases. Molecular aspects of medicine. 2008; 29: 258-89.

51. Mochizuki S, Soejima K, Shimoda M, Abe H, Sasaki A, Okano HJ, et al. Effect of ADAM28 on carcinoma cell metastasis by cleavage of von Willebrand factor. Journal of the National Cancer Institute. 2012; 104: 906-22.

52. Fleming NI, Jorissen RN, Mouradov D, Christie M, Sakthianandeswaren A Palmieri M, et al. SMAD2, SMAD3 and SMAD4 mutations in colorectal cancer. Cancer research. 2013; 73: 725-35.

53. Massague J. TGFbeta in Cancer. Cell. 2008; 134: 215-30.

54. Ali IU, Schriml LM, Dean M. Mutational spectra of PTEN/MMAC1 gene: a tumor suppressor with lipid phosphatase activity. Journal of the National Cancer Institute. 1999; 91: 1922-32.

55. Juraver-Geslin HA, Durand BC. Early development of the neural plate: new roles for apoptosis and for one of its main effectors caspase-3. Genesis. 2015; 53: $203-24$

56. Guo J, Zhang K, Ji Y, Jiang X, Zuo S. Effects of ethyl pyruvate on myocardial apoptosis and expression of Bcl-2 and Bax proteins after ischemia-reperfusion in rats. Journal of Huazhong University of Science and Technology Medical sciences $=$ Hua zhong ke ji da xue xue bao Yi xue Ying De wen ban = Huazhong keji daxue xuebao Yixue Yingdewen ban. 2008; 28: 281-3.

57. Gou Y, Zhai F, Zhang L, Cui L. RUNX3 regulates hepatocellular carcinoma cell metastasis via targeting miR-186/E-cadherin/EMT pathway. Oncotarget. 2017; 8: 61475-86.

58. Vu T, Datta PK. Regulation of EMT in Colorectal Cancer: A Culprit in Metastasis. Cancers. 2017; 9. 
59. Li J, Yang R, Dong Y, Chen M, Wang Y, Wang G. Knockdown of FOXO3a induces epithelial-mesenchymal transition and promotes metastasis of pancreatic ductal adenocarcinoma by activation of the beta-catenin/TCF4 pathway through SPRY2. Journal of experimental \& clinical cancer research : CR. 2019; 38: 38 .

60. Liu H, Yin J, Wang H, Jiang G, Deng M, Zhang G, et al. FOXO3a modulates WNT/beta-catenin signaling and suppresses epithelial-to-mesenchymal transition in prostate cancer cells. Cellular signalling. 2015; 27: 510-8.

61. Kunz P, Sahr H, Lehner B, Fischer C, Seebach E, Fellenberg J. Elevated ratio of MMP2/MMP9 activity is associated with poor response to chemotherapy in osteosarcoma. BMC cancer. 2016; 16: 223.

62. Stetler-Stevenson WG. Tissue inhibitors of metalloproteinases in cell signaling: metalloproteinase-independent biological activities. Science signaling. 2008; 1: re6.

63. Murphy G. Regulation of the proteolytic disintegrin metalloproteinases, the 'Sheddases'. Seminars in cell \& developmental biology. 2009; 20: 138-45.

64. Du C, Huang D, Peng Y, Yao Y, Zhao Y, Yang Y, et al. 5-Fluorouracil targets histone acetyltransferases p300/CBP in the treatment of colorectal cancer. Cancer letters. 2017; 400: 183-93.

65. Brunen D, Willems SM, Kellner U, Midgley R, Simon I, Bernards R. TGF-beta: an emerging player in drug resistance. Cell cycle. 2013; 12: 2960-8.

66. Richter M, Dayaram T, Gilmartin AG, Ganji G, Pemmasani SK, Van Der Key $\mathrm{H}$, et al. WIP1 phosphatase as a potential therapeutic target in neuroblastoma. PloS one. 2015; 10: e0115635.

67. Mu WP, Wang J, Niu Q, Shi N, Lian HF. Clinical significance and association of RUNX3 hypermethylation frequency with colorectal cancer: a meta-analysis. OncoTargets and therapy. 2014; 7: 1237-45.

68. Ogino S, Meyerhardt JA, Kawasaki T, Clark JW, Ryan DP, Kulke MH, et al. CpG island methylation, response to combination chemotherapy, and patient survival in advanced microsatellite stable colorectal carcinoma. Virchows Archiv : an international journal of pathology. 2007; 450: 529-37.

69. Johnson AJ, Hsu AL, Lin HP, Song X, Chen CS. The cyclo-oxygenase-2 inhibitor celecoxib perturbs intracellular calcium by inhibiting endoplasmic reticulum Ca2+-ATPases: a plausible link with its anti-tumour effect and cardiovascular risks. The Biochemical journal. 2002; 366: 831-7.

70. Toyoshima T, Kamijo R, Takizawa K, Sumitani K, Ito D, Nagumo M. Inhibitor of cyclooxygenase- 2 induces cell-cycle arrest in the epithelial cancer cell line via up-regulation of cyclin dependent kinase inhibitor p21. British journal of cancer. 2002; 86: 1150-6.

71. Lonnroth C, Andersson M, Asting AG, Nordgren S, Lundholm K. Preoperative low dose NSAID treatment influences the genes for stemness, growth, invasion and metastasis in colorectal cancer. International journal of oncology. 2014; 45: 2208-20.

72. Wei C, Gao JJ. Downregulated miR-383-5p contributes to the proliferation and migration of gastric cancer cells and is associated with poor prognosis. PeerJ. 2019; 7: e7882

73. Li F, Aljahdali I, Ling X. Cancer therapeutics using survivin BIRC5 as a target: what can we do after over two decades of study? Journal of experimental \& clinical cancer research : CR. 2019; 38: 368.

74. Ren S, Xin Z, Xu Y, Xu J, Wang G. Construction and analysis of circular RNA molecular regulatory networks in liver cancer. Cell cycle. 2017; 16: 2204-11.

75. Choi YC, Yoon S, Byun Y, Lee G, Kee H, Jeong Y, et al. MicroRNA library screening identifies growth-suppressive microRNAs that regulate genes involved in cell cycle progression and apoptosis. Experimental cell research. 2015; 339: 320-32.

76. Shi X, Li Y, Sun Y, Zhao X, Sun X, Gong T, et al. Genome-wide analysis of IncRNAs, miRNAs, and mRNAs forming a prognostic scoring system in esophageal squamous cell carcinoma. PeerJ. 2020; 8: e8368.

77. Peng Y, Li H, Wu M, Wang X, Fan S, Liu F, et al. NGX6 inhibits AP-1 and Ets-1 expression and down-regulates cyclin D1 in human colorectal cancer. Acta biochimica et biophysica Sinica. 2009; 41: 504-14.

78. Ma J, Zhou J, Fan S, Wang L, Li X, Yan Q, et al. Role of a novel EGF-like domain-containing gene NGX6 in cell adhesion modulation in nasopharyngeal carcinoma cells. Carcinogenesis. 2005; 26: 281-91. 